
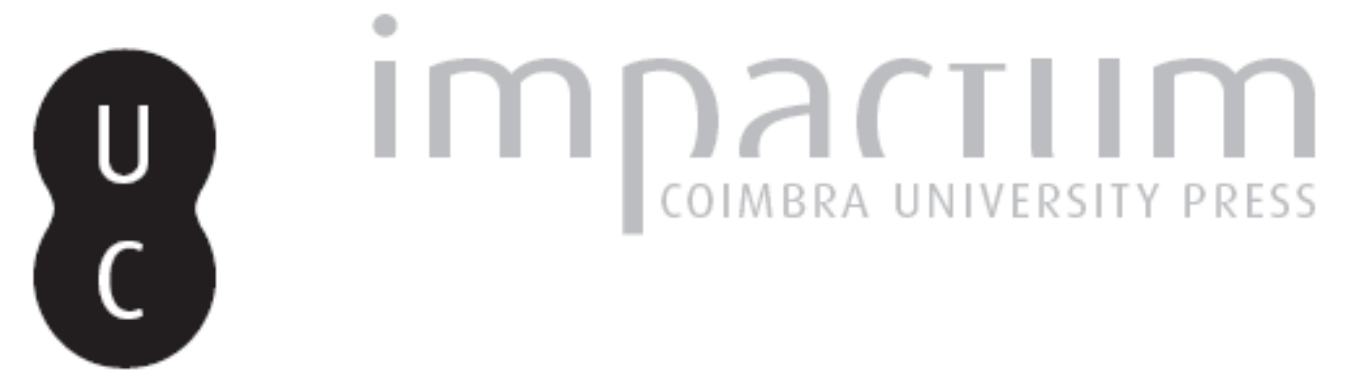

\title{
[Recensão a] Augusto de Miranda Pinho, Normas Práticas de Prospecção Arqueológica
}

\author{
Autor(es): D'Encarnação, José
}

Publicado por: Imprensa da Universidade de Coimbra

URL persistente:

URI:http://hdl.handle.net/10316.2/45450

DOI:

DOI:https://dx.doi.org/10.14195/1647-8657_35_11

Accessed : $\quad$ 26-Apr-2023 12:48:14

A navegação consulta e descarregamento dos títulos inseridos nas Bibliotecas Digitais UC Digitalis, UC Pombalina e UC Impactum, pressupõem a aceitação plena e sem reservas dos Termos e Condições de Uso destas Bibliotecas Digitais, disponíveis em https://digitalis.uc.pt/pt-pt/termos.

Conforme exposto nos referidos Termos e Condições de Uso, o descarregamento de títulos de acesso restrito requer uma licença válida de autorização devendo o utilizador aceder ao(s) documento(s) a partir de um endereço de IP da instituição detentora da supramencionada licença.

Ao utilizador é apenas permitido o descarregamento para uso pessoal, pelo que o emprego do(s) título(s) descarregado(s) para outro fim, designadamente comercial, carece de autorização do respetivo autor ou editor da obra.

Na medida em que todas as obras da UC Digitalis se encontram protegidas pelo Código do Direito de Autor e Direitos Conexos e demais legislação aplicável, toda a cópia, parcial ou total, deste documento, nos casos em que é legalmente admitida, deverá conter ou fazer-se acompanhar por este aviso.

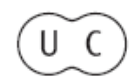


UNIVERSIDADE DE COIMBRA

FACULDADE DE LETRAS

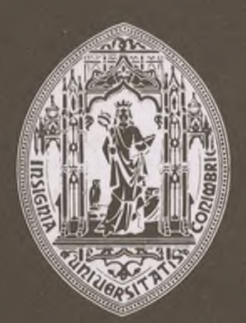

\section{CONIMBRIGA}

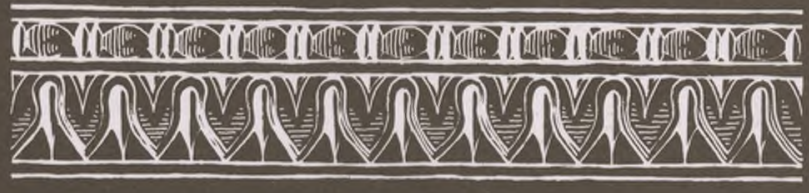

VOLUME XXXV - 1996 
sismos. E mais adiante, falando do templo de ísis, mais uma vez atribui a um sismo a sua destruição nos meados do séc. IV d. C. Parecem sismos a mais, e não podemos deixar de manifestar algumas dúvidas quanto às cronologias que aliás nem sempre estão de acordo com as propostas pelos autores das diversas monografias científicas sobre os monumentos da cidade.

$\mathrm{O}$ testemunho das cerâmicas africanas importadas parece aliás desmentir a ideia de uma cidade em ruínas no séc. III. Ou terão mesmo os habitantes de Bado vivido desde então numa cidade arruinada, como o autor pretende? Se a cronologia das edificações nos parece segura, a dos abandonos afigura-se-nos pouco convincente e algo estranha. Que dirão os autores das monografias, ainda não publicadas, do Capitólio e da basílica?

Mas “a situação anterior não podia durar sempre. Finalmente, os habitantes de Bado fizeram tábua rasa do passado: demoliram-se os muros que ameaçavam ruína, fizeram-se nivelamentos de tudo (supomos que o autor se refere ao forum) e surgiu uma nova cidade que pouco se assemelhava à antiga" (p. 61). Lamentamos que o autor nos diga tão pouco dessa nova cidade, que sobreviveu até aos inícios do séc. VII. Mesmo assim, não deixa de apresentar-nos as casas tardias que se ergueram sobre as ruínas do templo de Isis e do macellum.

A indústria de garum, que foi, sem dúvida, uma das principais actividades económicas da cidade, parece ter-se extinguido nos finais do séc. III: pelo menos, não há cetária em funcionamento atestada no séc. IV.

Com o autor, desejamos que as escavações de Baelo não sofram segundo eclipse, e que possam prosseguir concluída a publicação da série de monografias em curso. A presente obra constitui simultaneamente uma introdução a e um resumo dessas monografias, com pontos de vista originais; é uma obra essencial na bibliografia das cidades romanas da Espanha.

J. ALARCÃO

Augusto de Miranda PINHO, Normas Práticas de Prospecção Arqueológica. Edição de Autor, Amarante, 1989, 36 pp., ilustr.

Só agora este opúsculo me chegou às mãos; creio, porém, que nunca será tarde de mais para sobre ele tecermos algumas considerações.

Com mais de 80 anos (nascera em Amarante, a 22 de Agosto de 1904), já impossibilitado de ver, Miranda Pinho não perdeu o seu espírito de lutador pela causa do património e, bem industriado na escola da vida em que seu pai, o conhecido etnólogo José de Pinho, o educara, ditou, antes de falecer, estes leves apontamentos, no intuito de transmitir aos mais novos aquilo que um «saber de experiências feito» lhe proporcionara. Como escreveu Colette Magny, "quando um velho morre, é uma biblioteca que arde"; e Miranda Pinho quis evitar que... a biblioteca ardesse. Honra à sua memória!

Conimbriga, 35 (1996), p. 219-239 
Depois de apresentar o Autor e a sua obra, esclarece o Dr. Eduardo Jorge Lopes da Silva, na nota introdutória, que o livrinho "não se destina a eruditos"; foi, apenas, intenção singela torná-lo acessível "aos estudantes das nossas escolas, a todos aqueles que (...) gostem de calcorrear montes e vales com o fito de localizarem vestígios dos nossos mais longínquos antepassados» (p. 12).

E, na verdade, o livrinho é isso mesmo: uma conversa amena, salpicada de saborosas histórias, onde se explica como podem encontrar-se as coisas de antanho: as normas a observar; como se colhem informações; quais as melhores épocas para a prospecção (após as chuvas, aconselha...); cuidados a ter no recurso a cartas topográficas; os lugares a preferir... E, acima de tudo, a importância que detém a prospecção:

«Eu sei que é trabalho que se não vê e que, por isso, as autarquias lhe não dão os auxílios que seriam necessários, tanto mais que não rende votos e o IPPC não pode subsidiar tão vastos trabalhos" (p. 30).

Curiosamente, aqui e ali, a talhe de foice, vem a informação da necrópole, do lagar, da sepultura cavada na rocha, da ânfora com grafitos no bojo... achegas que os arqueólogos da região amarantina certamente não deixaram perder e que constituem importante manancial, inclusive para a história da investigação arqueológica em Portugal, ao tempo dum Leite de Vasconcelos, dum José Fortes ou dum Martins Sarmento, com quem, através do pai, Augusto de Miranda Pinho privou na sua juventude. E não falta a nota, pitoresca, de como a necrópole "lusitano-romana" sita "a cerca duns 80 metros do local denominado Ataúdes", no atalho que de Lufrei conduz a Amarante, não foi convenientemente explorada, porque $o$ terreno "pertencia a um 'talaça' e meu Pai e eu éramos republicanos", "o que prova", conclui com fina ironia — e flagrante actualidade!... —, "que a 'porca' da política até nos 'cacos' velhos se mete" (p. 25).

Aliás, Miranda Pinho não poupou a crítica, sempre que the pareceu oportuna (e oxalá nenhuma tenha caído em saco roto!). Assim, a propósito duma peça de cerâmica fora do comum que recolhera, acrescenta «que ainda se pode observar no já citado Museu de Amarante, aonde eu, em má hora, a depositei» (p. 23).

Tentei, por exemplo, identificar alguns desses dados soltos com as referências insertas no $1 .^{\circ}$ fascículo do II volume (pp. 24-25) de Roman Portugal, de J. Alarcão (Warminster, 1988), mas não é tarefa fácil, à primeira vista, dada a imprecisão dos elementos fornecidos quer por Miranda de Pinho quer pelos textos em que Jorge de Alarcão se baseou. Por exemplo: será a atrás referida necrópole a que vem mencionada no Roman Portugal sob o n. ${ }^{\circ} 418$, como sita em Quebrada, na freguesia de Lomba: "uma necrópole de incineração cujo espólio se reduz a cerâmica comum, difícil de datar", informação colhida precisamente num artigo de José Fortes (in Portugália 2 1905-1908, 252-262)?

Já sobre uma "estação eneolítica" cuja localização acaba por não precisar e de que trata nas pp. 23-24 se poderá ter mais sorte. Seu pai teria feito sobre ela uma comunicação na Sociedade Portuguesa de Antropologia e Etnologia e Afonso do Paço lograra enviar a um laboratório de Londres os restos carbonizados de "favas equinas e de sorgo" daí exumados. Miranda Pinho confessa que foram baldados os 
seus esforços para saber onde essas informações vieram a lume. Creio, no entanto, que os resultados obtidos por Afonso do Paço se poderão encontrar na comunicação intitulada "Nota sobre sementes proto-históricas e outras encontradas em Portugal», que apresentou ao III Congreso Nacional de Arqueologia (Galicia, 1953) e que vem nas pp. 510-515 das respectivas actas (Zaragoza, 1955). Por outro lado, seu pai também se referira ao assunto em 1930, por altura da celebração, em Coimbra e no Porto, do XV Congrès International d'Anthropologie et d'Archéologie Préhistorique, em intervenção a que deu o título de «Sur les graines trouvées dans la station énéolithique de Pepim - Amarante", que seria inserida a pp. 356-358 do volume de actas (Paris, 1931).

Ilustram o volumezinho, ao final, très estampas: urna sobre pedras oscilantes e gravuras rupestres da Serra da Aboboreira; as outras duas são fotografias de lagares abertos na rocha.

Uma obra singela, portanto; "ingénua" a poderiam qualificar espíritos de pendor mais radical. Em meu entender, é, exactamente por essas suas características, um livrinho a referir na história da Arqueologia nortenha. Não tanto pelo que explicita; sobretudo pelo que deixa subentender.

JOSÉ D'ENCARNAÇÃO

Arqueologia em Palmeia (1988/92), Palmeia, 1993, 84 pp., ilustr.

Perdem-se, amiúde, informações preciosas, porque louváveis iniciativas acabam por não ter eco em revistas da especialidade e circunscrevem-se, assim, a um circuito deveras reduzido. Essa a razão por que ouso dar sucinta conta do bem elaborado catálogo da exposição que, sob o título acima, foi levada a efeito na igreja de Santiago do castelo de Palmeia, de 28 de Agosto a 19 de Dezembro de 1993, numa acção concertada do Museu Municipal e do Departamento Sociocultural do respectivo município.

Aí se apresenta, em linhas gerais, num texto da autoria da Dra. Isabel Cristina Ferreira Fernandes, a carta arqueológica do concelho, com respectivo mapa de localização, e se expõem, por ordem cronológica (desde o Neolítico ao século $\mathrm{XVII}$ ), as peças mais significativas resultantes de prospecções efectuadas. As grutas artificiais da Quinta do Anjo - monumentos funerários do Neolítico Final e do Calcolitico - merecem lugar à parte (pp. 20-23). Seguem-se os testemunhos da presença romana descobertos no Zambujalinho (Herdade do Zambujal, freguesia de Marateca), com particular destaque para o abundante material anfórico, mormente da forma Dressel 14 (uma das asas tem a marca VENVS); expõem-se três moedas: uma de Constantino, cunhada na primeira oficina de Lugdunum; outra de Constâncio II; a terceira, de Constantino também, cunhada em Aquileia.

Da presença muçulmana e do período da Reconquista falam os materiais exumados e as estruturas arquitectónicas postas a descoberto no castelo de

Conimbriga, 35 (1996), p. 219-239 